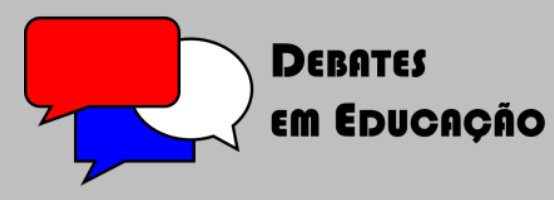

ISSN: $2175-6600$

Vol. 9 | №. 18 | Mai./Ago. | Ano 2017

Francisco Renato Lima Universidade Federal do Piauí (UFPI) fcorenatolima@hotmail.com

\title{
FORMAÇÃO, IDENTIDADE E CARREIRA DOCENTE: ENDEREÇANDO ITINERÁRIOS TEÓRICOS SOBRE O "SER PROFESSOR" NA CONTEMPORANEIDADE
}

\begin{abstract}
RESUMO
O objetivo deste estudo é discutir sobre formação, identidade e carreira docente como elementos articulados e estruturantes do processo educativo, a partir de um enfoque sócio-histórico. A articulação entre esses eixos considera as relações de pertencimento e reelaboração constante da imagem de si, em parceria com o outro, construídas pelo professor, no constate diálogo, interação e aprendizagem colaborativa, que legitimam sua trajetória profissional. Os desafios do 'ser professor' envolvem uma discussão de caráter político e pedagógico. $\mathrm{Na}$ pesquisa bibliográfica alguns pontos são destacados: uma formação docente de qualidade deve se dá por meio da relação que se estabelece entre teoria e prática, a partir do que o aluno é capaz de construir, analisando e interpretando a realidade por intermédio das fundamentações teóricas adquiridas durante o curso; a identidade docente vai sendo moldada paulatinamente, em um processo ininterrupto de (des) construção de si mesmo; e a carreira docente se constitui de fases ou ciclos de vida profissional, que não apresentam um aspecto linear, mas se desencadeiam e surgem ao longo da vida profissional, conforme os anos de serviço, e principalmente, determinadas pelos contextos de atuação profissional.
\end{abstract}

Palavras-chave: Formação de professores. Identidade docente. Carreira profissional.

\section{TRAINING, IDENTITY AND TEACHING CAREER: ADDRESSING ROUTES THEORY ON THE "TEACHER BE" IN CONTEMPORARY}

\begin{abstract}
The purpose of this study is to discuss teacher education, identity and careers as articulated and structuring elements of the educational process, based on a socio-historical approach. The articulation between these axes considers the relations of belonging and constant re-elaboration of the self image, in partnership with the other, built by the teacher, in the constant dialogue, interaction and collaborative learning, that legitimize his professional trajectory. The challenges of 'being a teacher' involve a discussion of a political and pedagogical nature. In the bibliographical research some points are highlighted: a quality teaching formation must take place through the relation that is established between theory and practice, from which the student is able to construct, analyzing and interpreting the reality through the theoretical foundations acquired during the course; the teacher identity is being gradually shaped, in an uninterrupted process of (de) constructing oneself; and the teaching career consists of phases or cycles of professional life, which do not present a linear aspect, but are triggered and arise during the professional life, according to the years of service, and mainly determined by the contexts of professional performance.
\end{abstract}

Keywords: Teacher training. Teaching identity. Professional career.

DOI: 10.28998/2175-6600.2017v9n18p119 


\section{CONSIDERAÇÕES INICIAIS}

Entender as mudanças e transformações que permeiam o contexto educacional demanda um repensar sobre os meandros e interfaces que envolvem uma tríade base da construção do "ser professor": os processos de formação docente, enquanto direito do professor, em situação de inacabado e que necessita de um contínuo aperfeiçoamento profissional; a definição da identidade profissional, no que se refere à superação dos dilemas históricos de sua fragmentação e que exige, portanto, a legitimação da sua cidadania; e a construção da carreira docente, em complementaridade aos demais enfoques, firma-se como um suporte de alcance a valorização profissional e desempenho em patamares de reconhecimento social exigidos pela sua própria função social, de mediador de possibilidades de aprendizagem.

Na medida em que se vislumbram novos horizontes, perspectivas e problemáticas na sociedade contemporânea, as questões de formação, identidade e carreira docente ganham novas "roupagens". Redefinem-se estratégias e mecanismos que deem conta de potencializar o processo de ensino e aprendizagem, e desta forma, "ser professor", implica em uma (des) construção social e cultural, comprometida com a ética, a democracia e a cidadania.

Muito embora já se tenha pesquisado, estudado e produzido neste campo, existem muitas questões a serem "olhadas" dentro dos cursos de formação docente, inicial e continuada; e principalmente, nas crenças e práticas arraigadas em modelos aplicacionistas, que não compreendem a educação como meio de transformação e mudança social.

Este estudo objetiva discutir sobre formação, identidade e carreira docente, como elementos articulados e estruturantes do processo educativo, a partir de um enfoque sóciohistórico aos adventos da contemporaneidade. A articulação entre esses eixos será construída a partir do estabelecimento de reflexões crítico-reflexivo sobre a docência, considerando esta, como um projeto processual e contínuo, que se articula as experiências e trajetórias de cada sujeito da educação, que em seu campo de atuação profissional, constrói relações de pertencimento e reelaboração constante da imagem de si, através do princípio da alteridade, advindo de Bakhtin (2011), que o faz, reconhecer e valorizar o constate diálogo, interação e aprendizagem colaborativa com o outro.

Nessa elucidação teórica, partiu-se dos fundamentos da pesquisa bibliográfica, de natureza qualitativa. Essa abordagem, tanto no ensino, quanto na pesquisa educacional, possibilita, segundo André (2000), que se problematize questões do cotidiano escolar, de 
modo complexo e multidimensional, relacionando fatos, opiniões e diferentes percepções que dialoguem e estabeleçam pontos de (di) convergência entre si, e desse confronto, seja possível, estabelecer uma unicidade criativa e produtiva sofre um determinado fenômeno. Tudo isso, conforme Chizzotti (2010, p. 84), acontece de modo sensível ao contexto histórico, sociocultural e político de onde advém as visões estudadas, pois, na realidade, os fenômenos "se manifestam em uma complexidade de oposições, de revelações e de ocultamentos", de modo que "é preciso ultrapassar a sua aparência imediata para descobrir a sua essência", e nisso, entra a questão da subjetividade, que de acordo com Minayo (2013), é parte integrante da singularidade do fenômeno social, fundado em uma época e um contexto particular.

Fundada nessa concepção qualitativa, a pesquisa bibliográfica busca, segundo Boccato (2006, p. 266),

[...] a resolução de um problema (hipótese) por meio de referenciais teóricos publicados, analisando e discutindo as várias contribuições científicas. Esse tipo de pesquisa trará subsídios para o conhecimento sobre o que foi pesquisado, como e sob que enfoque e/ou perspectivas foi tratado o assunto apresentado na literatura científica. Para tanto, é de suma importância que o pesquisador realize um planejamento sistemático do processo de pesquisa, compreendendo desde a definição temática, passando pela construção lógica do trabalho até a decisão da sua forma de comunicação e divulgação.

Essa reunião teórica, ou "planejamento sistemático do processo de pesquisa", como trata Boccato (2006), obedeceu aos seguintes passos: a) identificação de alguns dos principais autores que abordam o tema, considerados fontes consistentes e precursores na discussão; b) seleção dos conceitos-chaves por eles empregados na definição do objeto de estudo; c) conjugação, a partir de um entrelaçamento crítico e reflexivo, de suas ideias, de modo que elas convirjam para o alcance do objetivo do trabalho.

Sob esse enfoque, ancorou-se na produção bibliográfica de Behrens (2005), Frigotto (1996), Huberman (2000), Libâneo (2001), Shön (2000), Tardif (2010), Zeichner (1993), entre outros que aclarem o caminho da pesquisa; bem como, a orientações legais propostas na Lei 9. 394/96, que estabelece as diretrizes e bases da educação nacional.

As motivações acadêmico-científicas para realização desse estudo partem da necessidade de integrar-se ao coro de vozes já reconhecidas nesse campo, a exemplo, os autores referenciados neste estudo, com o propósito de delinear olhares e pôr em evidência, questões tão relevantes para o reconhecimento e valorização da docência na contemporaneidade. Ao situar-se em relação a alguns trabalhos produzidos na área, buscase, aprofundar a discussão sobre o tema, reconhecendo as contribuições que isso possa trazer para o desenvolvimento da pesquisa educacional. 
Ainda sobre a articulação entre estes três pontos - formação, identidade e carreira docente - esta iniciativa firma-se pelo reconhecimento da necessidade de discutir e aprofundar reflexões teórico-metodológicas sobre eles, no sentido de possibilitar um repensar sobre o papel da educação na atualidade, a importância do professor como ser do inacabado, em constante processo de atualização e aprendizagem, os desafios da prática docente em tempos contemporâneos. Dessa forma, na tessitura textual que se propõe neste estudo, os posicionamentos acerca de formação, identidade e carreira docente entrelaçam-se, entrecruzam-se e fundam-se entre si.

\section{FORMAÇÃO DOCENTE: (DES) CONTINUIDADES NA SUA CONSTITUIÇÃO SOCIAL}

Situar a questão da formação docente na atualidade urge a necessidade de resgatar a discussão a partir de uma vertente histórica dos fatos, que revelam a face das condições de ensino e aprendizagem no processo histórico de construção do saber escolar na sociedade. As implicações de um ensino, que muitas vezes apresenta-se difuso atualmente, é herança da forma como tudo começou, - a gênese do processo - que reflete implicações atualmente.

A literatura histórico-educativa consta que a partir de 1808, com a transferência da Corte portuguesa para o Brasil, surge a necessidade de formar profissionais que respondessem à nova situação; e neste contexto, foram implantados os primeiros cursos superiores, com seus currículos organizados de maneira desigual, baseando-se na supervalorização das ciências exatas e tecnológicas em detrimento das outras. O sistema seriado era composto de disciplinas com programas fechados, uma vez que os conteúdos visavam apenas à formação de um profissional competente em determinada área ou especialidade.

Em crítica a esses modelos, é importante ressaltar hoje, as importantes contribuições dos estudos sobre interdisciplinaridade na formação e na prática docente. Dentre eles, destacam-se as reflexões de Morin (2002/2011), quando trata do "pensamento complexo", em crítica as formas fragmentadas, simplificadas e redundantes de organização do saber. Também se conjuga a essa discussão, as postulações de Fazenda (1979/1994/2208), ao discutir sobre interdisciplinaridade; referindo-a como uma atitude pedagógica assentada no compromisso de uma educação centrada na condição humana e na eliminação das barreiras entre as pessoas, enfim, uma "atitude de abertura frente ao problema do conhecimento" (FAZENDA, 1979, p. 39). É, portanto, a partir das teorizações desses dois 
autores, principalmente, que se discute sobre temas como interdisciplinaridade, transdisciplinaridade, pluridiscplinaridade e multidisciplinaridade na formação de professores, reconhecendo os limites e aproximações teóricas e aplicadas entre os termos.

Retomando a abordagem histórica, aponta-se para o fato de que os primeiros professores de instituições de formação superior eram advindos das grandes universidades europeias e traziam grande bagagem cultural, porém o ensino atendia a uma didática diretiva, que cumpria ao professor, "dono do saber", ensinar; e ao aluno, receptor passivo deste saber, apropriar-se de maneira neutra, sem o discernimento crítico. Era um ensino que atendia as demandas de uma educação autoritária, que dentre outros fatores, culminava em uma avaliação sistemática e rigorosa que se pautava na ideia de julgar, vigiar, punir e outras terminologias que construíram uma imagem negativa e conflituosa sobre avaliação na prática educativa e que se perpetua até os dias atuais.

A crítica aos modelos adotados pelos sistemas educacionais não é assunto apenas na atualidade. A escrita literária de Raul Pompéia (1992, p. 129), em "O Ateneu”, de 1888, sua obra-prima e quase autobiográfica, como ele mesmo coloca, faz uma crítica ao sistema educacional vigente, afirmando que este é totalmente dependente do sistema social: "Não é o internato que faz a sociedade; o internato a reflete". Pompéia não se limita apenas a uma discussão de caráter interno, mas fere os princípios gerais e básicos da instituição.

É uma organização imperfeita, aprendizagem de corrupção, ocasião de contato com indivíduos de toda origem? O mestre é a tirania, o terror? O merecimento não tem cotação, cabrejam em linhas sinuosas da indignidade, aprova-se espionagem, a adulação, a humilhação, campeia a intriga, a maledicência, a calúnia, oprimem os prediletos do favoritismo, oprimem os maiores, os mais fortes, abundam as seduções perversas, oprimem os maiores, os mais fortes, abundam as seduções perversas, triunfam as audácias dos nulos? [...] Tanto melhor: é a escola da sociedade. (2007, p. 128).

Deste modo, é possível perceber os modelos de educação predominantes na época, em que a escola era um sistema organizado para cumprir uma função social, que em geral, estava de acordo com as demandas sociais, atendendo as necessidades das classes mais favorecidas, que tinha por objetivo formar um sujeito apto a assumir o seu espaço na sociedade de maneira produtiva e submissa. Assim, Pompéia (1992) caracterizou as instituições de ensino ainda, como reprodutoras de todos os malefícios e problemas que afetam a sociedade. Verifica-se, na obra, que a falta de limites associada à desconsideração pelos outros contribuem para que os jovens e adolescentes buscassem se impor pela força e pela ignorância, e neste sentido, a escola se configurava como uma mantenedora das desigualdades sociais, fato também não raro atualmente, quando figuram 
nos cenários escolares cenas de desrespeito e violência entre alunos e alunos, alunos e professores, professore e professores, entre outros sujeitos do espaço escolar.

Na escola tradicional, no processo de escolha dos profissionais para a docência, não havia uma preocupação com as questões didáticas e pedagógicas. Desconsideravam-se essas questões. Atualmente, estas crenças em relação à formação docente vêm sendo eliminadas do contexto escolar, pois se entende que uma formação docente de qualidade é um dos pilares que corroboram na melhoria do atual quadro educacional.

A questão da formação docente tem sido uma das demandas mais importantes da sociedade contemporânea, principalmente a partir da década de 1990, quando novas questões redimensionaram a educação e suas diferentes dimensões teóricas e práticas, ganhando um novo corpo discursivo, cujos enunciados vêm suscitando a necessidade da reflexão sobre os processos de formação docente, que deve ir além de uma ação mecânica e tecnicista, pautada no paradigma newtoniano-cartesiano da educação, materializado nas abordagens tradicional, escolanovista e tecnicista do ensino (BEHRENS, 2005); mas formar profissionais críticos, reflexivos, propositivos e revolucionários (SHÖN, 2000 / ZEICHNER, 1993), em seu fazer e em seu pensar, dando nova vida e rumo às estruturas dos modelos educativos.

A categoria "formação" inclui dimensões tais como: a valorização social, a capacidade de articular informações, percepções e conhecimentos necessários à sistematização das atividades, o desenvolvimento de habilidade que envolva as várias dimensões dos sujeitos, dando ênfase a sua capacidade critica e atuação autônoma.

Uma formação docente de qualidade deve se dá por meio da relação que se estabelece entre teoria e prática, a partir do que o aluno é capaz de construir, analisando e interpretando a realidade por intermédio das fundamentações teóricas adquiridas durante o curso. Atender a esta demanda, é essencial o investimento em pesquisas e meios que valorizem o processo contínuo de formação do profissional da educação, por isso, os cursos de formação de professores devem orientar, dar sentido e viabilizar, intencionalmente, condições para o pensar e o agir, por meio da organização e proposição do processo de ensino e aprendizagem.

A garantia de uma formação docente, com qualidade, que responda efetivamente as necessidades e desafios dos contextos educativos atuais está na Lei de Diretrizes e Bases da Educação Nacional - LDB, lei n 9.394 / 96, mais precisamente nos Artigos 61 e 62, que asseguram algumas condições fundamentais para a formação dos profissionais da educação: 
Art. 61. A formação de profissionais da educação, de modo a atender aos objetivos dos diferentes níveis e modalidades de ensino e às características de cada fase do desenvolvimento do educando, terá como fundamentos:

I - a associação entre teorias e práticas, inclusive mediante a capacitação em serviço;

II - aproveitamento da formação e experiências anteriores em instituições de ensino e outras atividades.

Art. 62. A formação de docentes para atuar na educação básica far-se-á em nível superior, em curso de licenciatura, de graduação plena, em universidades e institutos superiores de educação, admitida, como formação mínima para o exercício do magistério na educação infantil e nas quatro primeiras séries do ensino fundamental, a oferecida em nível médio, na modalidade Normal. (BRASIL, 1996, p. 25).

O debate acerca de políticas sobre formação de professores proposto pela lei é ampliado na discussão dos autores. Dentre eles, Weber (2000, p. 58), ao destacar:

O difícil processo de profissionalização do professorado, que vem envolvendo diversos setores sociais, governo e instâncias formadoras, a escola e a qualidade do ensino por ela ministrado constitui a principal preocupação, o que explicaria em parte o empenho governamental de definir uma política de formação que possa ter impacto imediato na escola. Ora, como se sabe, a consolidação do regime democrático impõe que as políticas públicas resultem do debate social, onde se confrontam projetos, decantam-se interesses, depuram-se propostas, eles próprios expressões de lutas sociais mais amplas.

A discussão aponta para a necessidade e importância de promover políticas que tragam resultados imediatos para a escola. Deste modo, a formação do profissional docente deve incluir a reflexão a partir de situações reais, diluindo-se assim, as dicotomias existentes entre teoria e prática, tornando-se um profissional prático-reflexivo que nos contextos aplicados, onde vivencia dúvidas e incertezas, possa recorrer à investigação como uma forma de decidir e de intervir significativamente em tais contextos, fazendo surgir novas concepções para a prática (SCHÖN, 2000). Portanto, na base de formação docente, deve está inclusa a capacidade de auto-reflexão sobre a prática docente, com vistas a compreender e interpretar a realidade social, e começar a construir a identidade docente, discussão que se inicia a seguir.

\section{IDENTIDADE DOCENTE: DA CONSTRUÇÃO, RECONHECIMENTO E DA VALORIZAÇÃO SOCIAL}

Desde há muito tempo, questões relativas à construção e fortalecimento da identidade docente, no enfrentamento e superação da crise de desvalorização e falta de reconhecimento ao profissional da docência, estão no topo das discussões teóricas que constituem os cursos de formação de professores; e principalmente, nas experiências 
práticas, que dão conta de testemunhar uma luta por reconhecimento e valorização da categoria.

O processo de construção da identidade docente começa mesmo antes que o professor se efetive em tal função ou mesmo tome consciência disso. O primeiro passo dessa jornada se dá ainda na escolha pelo curso superior, e ao entrar na instituição de ensino superior, ele começa a definir as primeiras bases de materialização e sistematização de um processo que não se finda, mas se renova e encontra novas veredas no caminho do "ser professor".

Ser professor em tempos contemporâneos, marcado pelas grandes transformações nos modos de pensar e organizar o conhecimento humano torna-se cada vez mais desafiante. O processo de globalização e automação da vida social, política, econômica e cultural, influencia todos os setores sociais; e as questões referentes, principalmente à educação, ganham novas "caras", emergem problemas novos, os velhos ressuscitam, e, portanto, novos olhares precisam ser lançados aos cursos de formação docente, e principalmente, às práticas desenvolvidas no espaço de sala de aula.

Componente fundamental nessa receita é a mudança nos moldes dos cursos de formação de professores, conforme tratou-se anteriormente, pois "sem uma sólida base teórica e epistemológica, a formação e profissionalização do educador reduz-se a um adestramento e a um atrofiamento das possibilidades de [...] analisar as relações sociais, os processos de poder e de dominação" (FRIGOTTO, 1996, p. 95), e isso refletirá diretamente nos rumos que tomará na vida profissional e consequentemente, na construção de sua identidade.

A luta pela construção de uma "identidade nacional" da categoria docente, ganha espaço, ainda que timidamente, no escopo teórico-epistemológico das pesquisas em educação, principalmente a partir da década de 90 do século XX, nos cursos de formações de professores, em nível stricto sensu (mestrado e doutorado), onde se discute sobre:

\footnotetext{
A identidade e profissionalização docente surge como tema emergente nos últimos anos, e abre perspectivas para questões de grande interesse e atualidade, como a busca da identidade profissional do docente, a relação do professor com as práticas culturais, questões de carreira, organização profissional e sindical, e questões de gênero (ANDRÉ; ROMANOWSKI, 1999, p. 3).
}

Acerca desse construto, o qual se dá cotidianamente, no espaço do pensar e do fazer docente nos processos de ensino e aprendizagem, a identidade define-se pelo contato e interação com diversas referências que se "encontram" no espaço escolar, nos conhecimentos que tem de si e do outro (BAKHTIN, 2011) - a alteridade nas relações humanas, a qual reconhece os outros, os pares no processo de construção da 
professoralidade. Caldeira (2000, p. 3) aponta que essa identidade "se constitui na relação com o outro: com os estudantes, com outros docentes, com as famílias, com a instituição escolar, etc. O contraste só é possível quando o/a professor/a se defronta com o outro, e é na relação pedagógica em que ele tem início".

Assim, a identidade docente vai sendo moldada paulatinamente, em um processo ininterrupto de (des) construção de si mesmo, que se aproxima com a questão da formação e carreira docente. O autor (CALDEIRA, 2000, p. 2) ainda é caro à discussão, ao refletir que:

[...] a identidade profissional docente não é algo que pode ser adquirido de forma definitiva e externa. Ela é movediça e constitui-se num processo de construção/desconstrução/reconstrução permanente, pois cada lugar e cada tempo demandam redefinições na identidade desse profissional. Trata-se, assim, de um processo de produção do sujeito historicamente situado. Ela ocorre, portanto, em um determinado contexto social e cultural em constante transformação, refletindo um processo complexo de apropriação e construção que se dá na interseção entre a biografia do docente e a história das práticas sociais e educativas, contendo, deste modo, as marcas das mais variadas concepções pedagógicas.

Como resposta a esse processo, há de se reconhecer as mudanças, ainda que tímidas, no tocante, por exemplo, as representações contidas no imaginário social, relacionadas à identidade docente, fator que em muito influencia o processo de legitimação social da identidade docente. Nas últimas décadas, pode-se acompanhar um avanço positivo no que diz respeito a isso, pois cada vez mais o profissional da educação afirma e comprova sua eficiência, mostrando o quão é necessária sua presença em diferentes espaços sociais. No caso do pedagogo, por exemplo, sua presença é necessária em todo e qualquer espaço em que haja uma prática educativa, intencional ou não e que requeira uma intervenção educativa, que se dar mediante variadas formas, por meio de diferenciadas estratégias, habilidades e procedimentos que respondam na prática, aos desafios atuais.

A título de ilustração, este exemplo situa a importância do professor para a construção da sociedade, que necessita de sua intervenção a todo o momento; requerente dele, um processo contínuo de formação, como parte da construção de sua identidade, e que se insere dentro de um projeto de carreira docente, - discussão que se trava a seguir. 


\section{CARREIRA DOCENTE: CONTÍNUOS ENLACES NO DESENVOLVIMENTO PROFISSIONAL}

A busca pela excelência no ensino e o desenvolvimento profissional docente são processos interdependentes, que ocorrem guiados pelas transformações socioculturais, políticas e econômicas de seu tempo, e associam-se diretamente com a concepção articulada entre formação, identidade e carreira docente. Sobre esta última, os desafios tornam-se cada vez mais complexos, em vista da complexidade que envolve o tempo cronológico e as questões sociais a que está intimamente ligada.

A discussão sobre esse tema envolve também, questões de reconhecimento social e salarial, considerando-os como indissociáveis, visto que na sociedade capitalista em que se vive, uma coisa está atrelada a outra, ou seja, as condições econômicas definem o social do indivíduo, e, por conseguinte, melhores condições de vida.

Concordando com esse entendimento, Libâneo (2001, p. 65) aponta que "as condições de trabalho e a desvalorização social da profissão de professor, de fato, prejudicam a construção da identidade dos futuros professores com a profissão", e, por conseguinte, a carreira docente como um todo, no qual se inclui a questão da formação e da identidade.

Em estudos sobre os ciclos de vida na constituição da identidade e carreira docente, Huberman (2000) buscou responder questões envolvendo a imagem que os professores têm de si mesmo e a satisfação na carreira, o que envolve as crises e desgastes da profissão e, também, em que medida isso interfere na competência do professor, de acordo com a quantidade de anos na carreira. $O$ autor divide essa carreira em sete fases; assim enumeradas: 1) Entrada na carreira; 2) Fase de estabilização; 3) Fase de diversificação; 4) Pôr-se em questão; 5) Serenidade e distanciamento afetivo; 6) Conservantismo e lamentações; 7) O desinvestimento.

A "entrada na carreira" ocorre no período de 1 a 3 anos de início na carreira docente, em que os professores passam por um estágio de descoberta, ao vivenciarem os primeiros desafios e obstáculos inerentes a profissão, equilibrando-se entre o entusiasmo e a insegurança (HUBERMAN, 2000).

A "fase de estabilização" ocorre quando o professor já está entre 4 e 6 anos de profissão, e consolida sua escolha profissional no meio social, demonstrando independência, confiança, segurança e competência nas atividades que desempenha (HUBERMAN, 2000). 
A "fase de diversificação" apresenta-se no período entre 7 e 25 anos na profissão, em que os professores enfrentam os desafios de vivenciarem novas experiências e têm que aprender a dinamizar suas aulas, por meio da renovação de suas práticas pedagógicas, pela utilização de recursos didáticos e tecnológicos, entre outros (HUBERMAN, 2000).

Quanto à fase de "pôr-se em questão", essa ocorre no período entre 15 e 25 anos na profissão, quando os professores questionam suas próprias ações, sobre os resultados efetivos resultantes de suas ações como professores, e nessa fase análise, eles sentemse frustrados ou realizados pelo alcance de seus objetivos (HUBERMAN, 2000).

A "serenidade e distanciamento afetivo" ocorre quando o professor está entre 25 a 35 anos de carreira, e se sente 'a vontade' em sua profissão, sem preocupar-se com julgamentos e também não investe na carreira, pois não sente a necessidade de provar mais nada naquilo que fazem, distanciando-se dos alunos (HUBERMAN, 2000).

Já a fase de "conservantismo e lamentações" também ocorre entre 25 a 35 anos de profissão, quando o professor apresenta resistências às mudanças decorrentes dos novos tempos, exaltando o passado e demonstrando insatisfação com a indisciplina dos alunos, o sistema de ensino, os colegas de trabalho, entre outras formas de expressarem suas angustias (HUBERMAN, 2000).

E por fim, a fase de "desinvestimento" ocorre quando o professor já tem entre 35 a 40 anos de carreira e apresentam-se frustrados por não terem conseguido alcançar seus objetivos durante toda a carreira e diante disso, são desmotivados e desinteressados pelo o que fazem (HUBERMAN, 2000).

Essas fases do ciclo de vida profissional dos professores não apresentam um aspecto linear, ou seja, não são segmentadas obrigatoriamente sob esta ordem, mas se desencadeiam e surgem no processo de carreira docente, de acordo com os anos de serviço, mas principalmente, determinadas pelos contextos de atuação profissional. Nas palavras de Ricardo (2007) essas fases constituem as "metamorfoses dos professores".

Os contextos de atuação docentes apresentam-se cada vez mais conflitosos e marcados por situações complexas e tensas, como a desvalorização social, violência (física ou simbólica) e diversas outras faces do desrespeito generalizado no espaço escolar, que fragmentam a prática do professor e consequentemente, a aprendizagem do aluno. Essa complexidade, identificada na leitura de Huberman (2000), corrobora para a construção de um quadro generalizado de insatisfação, comodismo e ineficácia na educação, visto que os professores, considerados como força-motriz no processo educacional, apresentam-se frágeis, passivos e descrentes naquilo que fazem. 
Esses desnivelamentos vivenciados na conjugação teoria e prática (ou justamente uma falta de coerência entre esses eixos!?), têm se tornado cada vez mais presentes nos discursos dos professores, que em situação de incompletude e silenciamento, fazem parte de um quadro de desmantelo e desordem velada nas bases dos processos de ensino e aprendizagem. Assim, diante da complexidade dessa questão, torna-se relevante uma breve discussão acerca dos significados da docência e as representações do "ser professor" em tempos contemporâneos, consideradas as configurações que a profissão assume socialmente, conforme se trata a seguir.

\section{OS SIGNIFICADOS DA DOCÊNCIA E AS REPRESENTAÇÕES DO “SER PROFESSOR” EM TEMPOS CONTEMPORÂNEOS}

As trajetórias de formação, identidade e carreira docente desembocam na construção do verdadeiro sentido do "ser professor" na contemporaneidade. Por tabela, esta é uma profissão marcada pela articulação entre trajetórias que envolvem o tempo - o pensado, o regido e o vivido -, consubstanciado pelos domínios políticos, pedagógicos, culturais, ideológicos e sociais, em nome de uma ação social para o bem coletivo: a educação, desvelada sua face primeira no espaço diálogo da sala de aula, na relação entre professor e aluno.

A construção do 'ser professor' envolve atualmente, um intrincado processo de idas e vindas, perpassando por fases de avanços e retrocessos, que envolvem o percurso individual de cada professor e as representações coletivas, construídas socialmente. Desse modo, reflete-se que as representações sociais e simbólicas do "ser professor" fazem parte das discussões de muitos jovens em suas escolhas profissionais e também de docentes em ação, que reavaliam suas escolhas e buscam ressignificar seus sentidos em meio a tantos problemas vivenciados pela educação. Dos primeiros, as representações advêm das experiências tidas como discente na escola básica, com seus antigos professores, bem como das representações dos "outros", que compõem o imaginário social acerca da profissão professor. Dos segundos, as representações fazem parte do tempo presente, das experiências cotidianas vivenciadas no espaço na sala de aula e nas esferas de reconhecimento (ou falta!?) do professor na sociedade.

Isso tudo é motivado, segundo Vesentini (2002, p. 235) porque existe um discurso na sociedade, de que "a carreira docente, com exceção da universitária era e ainda é, em grande parte, vista como algo destinado tão-somente àqueles que não têm competência para exercer outras atividades". Essa situação acarreta muitas complicações que 
fragmentam a construção da identidade e o reconhecimento da importância do professor nas bases estruturantes de uma sociedade desenvolvida. Em contrapartida a esses desdobramentos, Isaia; Bolzan (2003, p. 2) chama a atenção para o entendimento de que

A construção do papel de ser professor é coletiva, se faz na prática de sala de aula e no exercício de atuação cotidiana seja na escola seja na universidade. É uma conquista social, compartilhada, pois implica em trocas e representações. Assim, as formas mais úteis de representação das ideias, as analogias, ilustrações, exemplos, explicações e demonstrações, a maneira de representar e formular a matéria, para torná-la compreensível, revela a compreensão do processo de ensinar e de aprender pelo professor. O domínio desses aspectos é fundamental na construção do conhecimento pedagógico pelo professor.

Dessa forma, a formação do profissional da educação precisa está alicerçada por uma organização sistêmica, envolvendo uma gama de fatores culturais, políticos e ideológicos, considerando as experiências advindas das vivências pessoais e profissionais desse professor no contexto da sala de aula, uma vez que os desafios que se impõem na relação professor $X$ aluno pressupõem uma relação dialética, recíproca e de encontro de culturas e saberes, exigindo, deste modo, que

Os saberes profissionais dos professores parecem ser, portanto, plurais, compósitos, heterogêneos, pois trazem à tona, no próprio exercício do trabalho, conhecimentos e manifestações do saber-fazer e do saber-ser bastante diversificados e provenientes de fontes variadas, as quais podemos supor também que sejam de natureza diferente. (TARDIF, 2010, p. 61)

O autor chama atenção diretamente para os desafios enfrentados em sala de aula, uma vez que é neste espaço que a ação educativa efetivamente acontece. De onde quer que partam as discussões, baseadas em quaisquer que sejam as correntes filosóficas, políticas e sociais, é na sala de aula que são estreitadas as relações entre conhecimentos científicos historicamente produzidos e saberes vivenciais, oriundos das experiências particulares de cada sujeito da aprendizagem: professores e alunos (LIMA; SILVA, 2016).

É dessas vivências em sala de aula que os significados da docência e as representações do "ser professor" na atualidade vão sendo reconhecidos ao longo toda a carreira docente, que começa com a formação: inicial e continuada, e vai sendo aperfeiçoada e apreendida no cotidiano, no enfrentamento aos desafios e as dicotomias da prática. Deste modo, o trabalho docente é uma ação laboral, que exige do professor um envolvimento constante as questões sociais mais sensíveis de seu tempo, agindo criticamente sobre elas, de modo a transformar sua prática, e assim, contribuir para a melhoria da educação em geral.

A legítima constituição do 'ser professor' parte, portanto, do reconhecimento de que formação, identidade e carreira docente constituem um caminho uno, uma luta contínua, 
sempre inconclusa, na busca pelo aperfeiçoamento da prática, conscientes de que "o domínio de uma profissão não exclui o seu aperfeiçoamento, ao contrário será mestre quem continuar aprendendo" (BRANDÃO, 2007, p. 48). Assim, a volúpia do movimento e da reflexão crítica e contínua (ação-reflexão-ação) deve ser sempre, o mote desenfreador da melhoria da ação do professor em sala de aula e dos processos de ensino e aprendizagem.

\section{CONSIDERAÇÕES FINAIS}

A leitura que se propões neste estudo, constituiu um itinerário entre importantes eixos orientadores do modo de pensar e fazer educação na atualidade, conjugando da ideia de que formação, identidade e carreira docente são questões teórico-práticas que se entrelaçam e se definem uma em relação à outra. Impossível é pensá-las separadamente. Tão pouco, praticá-las de modo isolado. São conceitos próximos no plano teórico, e que se "aconchegam" ainda mais, na prática educativa, lócus onde são tecidos os fios do 'ser professor'.

A formação docente - inicial e continuada - é o espaço em que se constroem os sentidos e as aprendizagens que definem a identidade docente. Esta inclui uma construção que particulariza e potencializa o sujeito durante a carreira docente. Esta como o curso de vida profissional construída ao longo das experiências vividas em sua trajetória na educação.

Os desafios do 'ser professor' na atualidade pressupõe o reconhecimento da categoria, o que implica uma autonomia contextualizada nos âmbitos individuais e coletivos; o investimento em políticas de formação e aperfeiçoamento da prática docente; condições de trabalho que garantam o acesso e permanência não só do aluno na escola, mas do professor, para a manutenção do exercício dialético de ensinar e aprender continuamente. Nessa perspectiva, Lima (2008, p. 197), aponta para a efetivação de um processo de formação docente, de maneira ativa e reflexiva, baseado nos quatros pilares da educação, isto é, "aprender a aprender; aprender a ser; aprender a conviver; e aprender a fazer".

A profissão do professor/educador se concretiza no seu fazer pedagógico. Disso, pode-se inferir: o professor é, por excelência, o combustível da educação. Não se pretende com isso, dizer que ele sozinho realiza a educação, pois o ensino e a aprendizagem dependem de uma série de outros fatores, para além de sua ação em sala de aula, no entanto, é ele que assume frentes de atuação política e pedagógica na formação do aluno.

"Ser professor" então, nesse contexto, é tomar para si a responsabilidade e o compromisso ético e epistemológico de buscar a formação continuamente, para que isso 
Ihe garanta, dentro de seu espaço de ação profissional, a congregação de valores e condutas, viabilizadoras da construção social de seu trabalho, como sujeito dinâmico, crítico e reflexivo, que assume múltiplas identidades. Nesse percurso, sua carreira docente é delineada por diferentes momentos e experiências de interação e aprendizagem colaborativa, que repercutem diretamente na mudança social, que se espera advir da educação.

O levantamento bibliográfico feito neste estudo permitiu, acima de tudo, entender a docência como um espaço dinâmico, social e historicamente construído no diálogo entre teoria e prática, recorrendo à consciência histórica da sociedade, a busca pela mudança e constante aperfeiçoamento profissional. Deste modo, urge da sociedade, o reconhecimento e a valorização da importância desse profissional. Esta mudança não se dará ao acaso, mas de forma intencional, através de um trabalho coletivo em âmbito político educacional e pedagógico, envolvendo discussões e debates comprometidos com um projeto de educação de qualidade. Somente após esta conscientização, é que o professor terá seu lugar reconhecido e respeitado na sociedade, e poderá enfim, desenvolver um ensino de qualidade na prática.

\section{REFERÊNCIAS}

ANDRÉ, Marli Afonso de; ROMANOWSKI, Joana Paolim. Estado da arte sobre a formação de professores nas dissertações e teses dos programas de pós-graduação das universidades brasileiras (1990-1996). Reunião Anual da ANPEd, 22, Anais....[CD-ROM], Caxambu, 1999.

ANDRÉ, M. E. D. A. A pesquisa no cotidiano escolar. In: FAZENDA, I. (Org.). Metodologia da pesquisa educacional. 6. ed. São Paulo: Cortez, 2000. p. 35-45.

BAKHTIN, Mikhail. Estética da criação verbal. Tradução de Paulo Bezerra. 6. ed. São Paulo: Martins Fontes, 2011.

BEHRENS, Marilda Aparecida. O paradigma emergente e a prática pedagógica. Petrópolis: Vozes, 2005.

BRASIL. Lei Federal no 9. 394. Lei de diretrizes e bases da educação nacional. Brasília, DF: MEC, 1996.

BRANDÃO, Carlos Rodrigues. O que é educação? São Paulo: Brasiliense, 2007. 
BOCCATO, V. R. C. Metodologia da pesquisa bibliográfica na área odontológica e o artigo científico como forma de comunicação. Rev. Odontol. Univ. Cidade São Paulo, São Paulo, v. 18, n. 3, p. 265-274, 2006.

CALDEIRA, Ana Maria Salgueiro. A história de vida como instrumento para compreensão do processo de construção da identidade docente. Encontro Nacional de Didática e Prática de Ensino (ENDIPE), 10, Anais... [CD-ROM], Rio de Janeiro, 2000.

CHIZZOTTI, Antonio. Pesquisa em ciências humanas e sociais. 11. ed. São Paulo: Cortez, 2010.

FAZENDA, Ivani Catarina Arantes (Org.). Integração e interdisciplinaridade no ensino brasileiro: efetividade ou ideologia? São Paulo: Loyola, 1979.

(Org.). O que é interdisciplinaridade? São Paulo: Cortez, 2008.

Interdisciplinaridade: história, teoria e pesquisa. 4. ed. Campinas: Papirus, 1994.

FRIGOTTO, G. A formação e a profissionalização do educador: novos desafios. In: GENTILI, P. e SILVA, T. T. (Orgs.). Escola S.A.: quem ganha e quem perde no mercado educacional do neoliberalismo. Brasília: CNTE, 1996.

ISAIA, Silvia Maria de Aguiar; BOLZAN, Doris Pires Vargas. Formação do professor do ensino superior: um processo que se aprende? Centro de educação. Santa Maria, 2003, v. 29, n.2.

HUBERMAN, M. O ciclo de vida profissional dos professores. In: NÓVOA, A. Vidas de professores. Tradução de Maria dos Anjos Caseiro e Manuel Figueiredo Ferreira. Porto: Porto, 2000.

LIBÂNEO, J. C. O professor e a construção da sua identidade profissional. In: Organização e gestão da escola: teoria e prática. Goiânia: Alternativa, 2001.

LIMA, Maria do Socorro Lucena. Reflexão Sobre o Estágio/Prática de ensino na formação de Professores. Diálogo Educ. Curitiba, v.8, n. 23 p. 195. 205, jan/abr. 2008.

LIMA, Francisco Renato; SILVA, Jovina da. A universidade rumo a educação para a autonomia e superação da crise dos paradigmas modernos. In: SILVA, Jovina da; LIMA, 
Francisco Renato (Orgs.). Ensino Superior: concepção, avaliação e planejamento. Teresina: FUESPI, 2016, v. 1, p. 17-36.

MINAYO, M. C. S. (Org.). Pesquisa Social: teoria, método e criatividade. 33. ed. Petrópolis: Vozes, 2013.

MORIN, Edgar. Os sete saberes necessários à educação do futuro. 2. ed. São Paulo: Cortez; Brasília, DF: UNESCO, 2011.

A cabeça bem-feita: repensar a reforma, reformar o pensamento. Trad. Eloá Jacobina. 7. ed. Rio de Janeiro: Bertrand Brasil, 2002.

POMPÉIA, Raul. O Ateneu. 6. ed. São Paulo. Companhia das Letras. 1992.

RICARDO, Luís Filipe Firmino. Ensinar \& aprender. Revista eletrônica para professores, formadores e educadores (2007). Disponível em: < http://revistaensinareaprender.blogspot.com/2007/10 >. Acesso em: 01 jan 2014.

SHÖN, Donald. A. Educando o profissional reflexivo: um novo design para o ensino e para a aprendizagem. Porto Alegre: Artmed, 2000.

TARDIF, M. Saberes docentes e formação profissional. 10. ed. Petrópolis: Vozes, 2010.

VESENTINI, José William. A Formação do Professor de Geografia: algumas reflexões. In: PONTUSCHKA, Nídia Nacib; OLIVEIRA, Ariovaldo Umbelino de (Org.). Geografia em Perspectiva. São Paulo: Contexto, 2002. p. 255- 240.

WEBER, Silke. Políticas de formação de professores. In: CANDAU, Vera Maria (Org.). Cultura, linguagem e subjetividade no ensinar e aprender. Rio de Janeiro: DP\&A, 2000.

ZEICHNER, Kenneth M. A formação reflexiva de professores: ideias e práticas. Lisboa: Educa, 1993. 